\title{
Hyperthermic intraperitoneal chemotherapy (HIPEC) for colorectal peritoneal metastases: still a necessity?
}

Authors: Vignesh Narasimhan FRACS1,2, Michael Flood MRCS1,2, Satish Warrier FRACS, MS ${ }^{1}$, Alexander Heriot FRACS, MBA, MD ${ }^{1,2}$

\begin{abstract}
Affiliations:
${ }^{1}$ Peter MacCallum Cancer Centre, Department of Surgical Oncology

2 Sir Peter MacCallum Dept. of Oncology, University of Melbourne
\end{abstract}

\section{Conflicts of interest and financial disclosures:}

The Authors have no conflicts of interest. There is no grant support or financial relationship associated with this study.

This manuscript has 995 words (including references)

Key Words: HIPEC, peritoneal disease, cytoreductive surgery

\section{Corresponding Author:}

Dr Vignesh Narasimhan

Vignesh.naras@gmail.com

This is the author manuscript accepted for publication and has undergone full peer review but has not been through the copyediting, typesetting, pagination and proofreading process, which may lead to differences between this version and the Version of Record. Please cite this article as doi: 10.1111/ans.15794

This article is protected by copyright. All rights reserved. 
Phone: +61 451121766;

This article is protected by copyright. All rights reserved. 
The management of peritoneal metastases (PM) remains one of the greatest challenges in patients with metastatic colorectal cancer (mCRC). While systemic chemotherapy renders good results in the treatment of colorectal liver metastases, it is poorly efficacious in the management of colorectal peritoneal metastases (CRPM). When treated with chemotherapy alone, five-year survival in patients with CRPM is less than five percent. ${ }^{1}$ Verwaal et $\mathrm{al}^{2}$ demonstrated in a randomised trial (RCT) that cytoreductive surgery (CRS) with mitomycin C based hyperthermic intraperitoneal chemotherapy offered a significantly improved survival compared to systemic chemotherapy alone (22.3 v 12.6 months). Subsequent studies utilised oxaliplatin as the HIPEC agent. Oxaliplatin had proven efficacy as first line systemic treatment in $\mathrm{mCRC},{ }^{3}$ and was found to be safe intraperitoneally. ${ }^{4}$ Studies reported a median survival of 27-32 months in selected patients when treated with CRS and oxaliplatin HIPEC.5, 6 To date, there are no prospective studies comparing the efficacy of different HIPEC agents. With no accepted consensus on the preferred HIPEC agent, the choice of oxaliplatin or mitomycin $\mathrm{C}$ is being based largely on country and institutional preference. ${ }^{7}$

Recent evidence from three RCTs has raised significant doubts about the efficacy of HIPEC, particularly oxaliplatin HIPEC. The PRODIGE 7 RCT compared outcomes following complete cytoreduction alone, and with the addition of oxaliplatin HIPEC. It reported no survival benefit with oxaliplatin HIPEC in addition to successful complete cytoreduction (41.7 v 41.2 months). Sub-group analysis did suggest potential benefit with HIPEC in patients with a PCI of 11-15. Worryingly however, those receiving HIPEC had a significantly higher complication rate $(24.1 \% \mathrm{v} 13.6 \%, \mathrm{p}=0.03)$. In the prophylactic setting, the ProphyloChip trial (NCT01226394) ${ }^{8}$ compared the utility of 'second look' CRS with oxaliplatin HIPEC versus standard surveillance for asymptomatic patients six months following primary tumour resection deemed high risk for peritoneal recurrence. High risk was defined as minimal CRPM resected with the primary, 
ovarian metastases or perforated primary tumour. While CRPM were found in $52 \%$ of patients undergoing second look surgery, there was no difference in three-year disease free (DFS) or overall survival (OS) between the two arms (79\% v 80\%). The COLOPEC RCT (NCT02231086) ${ }^{9}$ compared the use of adjuvant oxaliplatin HIPEC with adjuvant systemic chemotherapy versus adjuvant systemic chemotherapy alone after pT4 or perforated primary tumour resections. There was no difference in peritoneal metastasis free survival $(77 \% \mathrm{~V}$ $81 \%$ ) by diagnostic laparoscopy at 18 months in either group, with no difference in DFS and OS.

Despite their limitations, these RCTs are landmark studies in a field with paucity of high quality evidence. These trials have led to significant debate on the role of HIPEC, with some experts calling for CRS alone to become standard treatment, with HIPEC to be abandoned altogether. ${ }^{10}$

These studies highlight a number of salient points. Firstly, given these studies utilised oxaliplatin; it suggests that oxaliplatin is likely suboptimal as a HIPEC agent. Unlike mitomycin $C$, there is no randomised data supporting the use of CRS with oxaliplatin HIPEC. In the early 2000s, the use of oxaliplatin as a HIPEC agent coincided with its implementation as first line systemic therapy, ${ }^{3}$ as oncologists were possibly more confident in its efficacy. Additionally, 30 minutes of intraperitoneal exposure with oxaliplatin, compared to 90 minutes with mitomycin $\mathrm{C}$ perhaps made it more appealing to surgeons.

While the results of these studies support discontinuation of oxaliplatin as a HIPEC agent, they do not translate to abandoning HIPEC altogether. CRS with mitomycin $\mathrm{C}$ based HIPEC should still remain as the recommended treatment for resectable low volume CRPM. It does however bring to light the urgent need for further high quality research in this field. Advances in translational oncology and 
collaborative research would allow exploration into identifying other potential intraperitoneal agents, and evaluating other forms of intraperitoneal delivery of drugs to complement high quality cytoreductive surgery.

This article is protected by copyright. All rights reserved. 


\section{References}

1. Franko J, Shi Q, Goldman C, Pockaj B, Nelson G, Goldberg R, et al.

Treatment of colorectal peritoneal carcinomatosis with systemic chemotherapy: a pooled analysis of north central cancer treatment group phase III trials N9741 and N9841. J Clin Oncol. 2012;30(3):263-7.

2. Verwaal V, van Ruth S, de Bree E, van Slooten G, van Tinteren H, Boot H, et al. Randomized Trial of Cytoreduction and Hyperthermic Intraperitoneal Chemotherapy Versus Systemic Chemotherapy and Palliative Surgery in Patients With Peritoneal Carcinomatosis of Colorectal Cancer. J Clin Oncol. 2003;21(20):3737-43.

3. Cassinello J, Escudero P, Salud A, Marcos F, Pujol E, Perez-Carrion R, et al. Activity and safety of oxaliplatin with weekly 5-fluorouracil bolus and low-dose leucovorin as first-line treatment for advanced colorectal cancer. Clin Colorectal Cancer. 2003;3(2):108-12.

4. Elias D, Bonnay M, Puizillou JM, Antoun S, Demirdjian S, El OA, et al. Heated intra-operative intraperitoneal oxaliplatin after complete resection of peritoneal carcinomatosis: pharmacokinetics and tissue distribution. Ann Oncol. 2002;13(2):267-72.

5. Glehen O, Kwiatkowski F, Sugarbaker PH, Elias D, Levine EA, De Simone $\mathrm{M}$, et al. Cytoreductive surgery combined with perioperative intraperitoneal chemotherapy for the management of peritoneal carcinomatosis from colorectal cancer: a multi-institutional study. J Clin Oncol. 2004;22(16):3284-92.

6. Sluiter NR, Rovers KP, Salhi Y, Vlek SL, Coupe VMH, Verheul HMW, et al. Metachronous Peritoneal Metastases After Adjuvant Chemotherapy are Associated with Poor Outcome After Cytoreduction and HIPEC. Ann Surg Oncol. 2018;25(8):2347-56.

7. Van der Speeten K, Lemoine L, Sugarbaker P. Overview of the optimal perioperative intraperitoneal chemotherapy regimens used in current clinical practice. Pleura Peritoneum. 2017;2(2):63-72.

8. Goere D, Glehen O, Quenet F, Ducreux M, Guilloit J, Texier M, et al. Results of a randomized phase 3 study evaluating the potential benefit of a second-look surgery plus HIPEC in patients at high risk of developing colorectal peritoneal metastases (PROPHYLOCHIP- NTC01226394). Journal of Clinical Oncology. 2018;36(no. 15_suppl (May 20 2018) 3531-3531).

9. Klaver CEL, Wisselink DD, Punt CJA, Snaebjornsson P, Crezee J, Aalbers AGJ, et al. Adjuvant hyperthermic intraperitoneal chemotherapy in patients with locally advanced colon cancer (COLOPEC): a multicentre, open-label, randomised trial. Lancet Gastroenterol Hepatol. 2019;4(10):761-70.

10. Evrard S. Autopsy of an expert consensus: End of hyperthermic intraperitoneal chemotherapy in colorectal carcinomatosis. Eur J Surg Oncol. 2018;44(12):1845-6. 


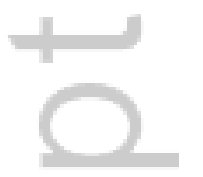




\section{University Library}

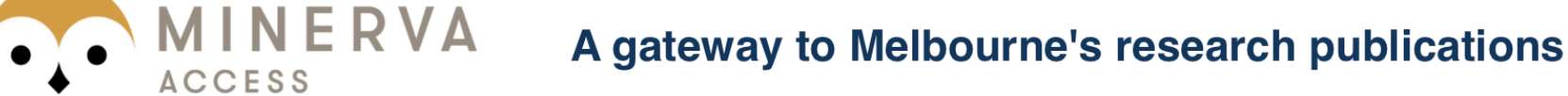

Minerva Access is the Institutional Repository of The University of Melbourne

Author/s:

Narasimhan, V;Flood, M;Warrier, S;Heriot, A

Title:

Hyperthermic intraperitoneal chemotherapy for colorectal peritoneal metastases: still a necessity?

Date:

2020-09-01

Citation:

Narasimhan, V., Flood, M., Warrier, S. \& Heriot, A. (2020). Hyperthermic intraperitoneal chemotherapy for colorectal peritoneal metastases: still a necessity?. ANZ JOURNAL OF SURGERY, 90 (9), pp.1541-1542. https://doi.org/10.1111/ans.15794.

Persistent Link:

http://hdl.handle.net/11343/276210 